\title{
IMPLEMENTASI METODE CONTRAST STRETCHING UNTUK PENAJAMAN CITRA DIGITAL
}

\author{
Iwan Yudis tiawan ${ }^{1)}$ \\ 1), iwanyudistiawan17@gmail.com
}

\begin{abstract}
Abstrak
Citra dengan kontras rendah mempunyai kualitas yang relatif kurang baik, informasinya sulit untuk diinterprestasikan secara langsung oleh mata manusia. Citra seperti ini dapat diperbaiki kualitasnya dengan Metode Contrast Stretching (Peregangan Kontras). Untuk menyelesaikan masalah tersebut dapat menggunakan Metode Contrast Stretching Untuk Penajaman Citra Digital. Metode ini dilakukan dengan cara operasi titik (point operations), yang akan memproses tiap piksel citra masukan secara individu, yaitu dengan membuat titik yang cenderung gelap menjadi lebih gelap dan yang cenderung terang menjadi lebih terang. Pengembangan perangkat lunak peningkatan kontras citra dilakukan menggunakan Borland Delphi 2010 Embarcadero.

Pengujian dilakukan pada citra standar yang berupa citra warna (color images) dengan format file BMP dan JPG. Berdasarkan pengujian pada beberapa sampel citra uji menunjukkan bahwa perangkat lunak yang dirancang dapat digunakan untuk meningkatkan kontras suatu citra.
\end{abstract}

Kata Kunci $\quad$ : Contrast Stretching, Point Operation, Citra Digital, Peningkatan Kontras, Borland Delphi.

\begin{abstract}
Low contrast images have relatively poor quality, the information is difficult to interpret directly by the human eye. This image can be improved in quality with the Contrast Stretching Method. To solve this problem, you can use the Contrast Stretching Method for Digital Image Sharpening. This method is carried out by means of point operations, which will process each pixel of the input image individually, that is by making the points that tend to be darker become darker and which tend to be brighter and brighter. The development of image contrast enhancement software was carried out using Borland Delphi 2010 Embarcadero.

Tests are carried out on standard images in the form of color images with BMP and JPG file formats. Based on testing on several samples of test images shows that the software designed can be used to improve the contrast of an image.
\end{abstract}

Keywords: Contrast Stretching, Point Operation, Digital Image, Increased Contrast, Borland Delphi.

\section{PENDAHULUAN}

Sekarang ini penggunaan citra digital semakin meningkat karena kelebihan-kelebihan yang dimiliki oleh citra digital tersebut, antara lain kemudahan dalam mendapatkan gambar , memperbanyak gambar, pengolahan gambar dan lain-lain. Tetapi tidak semua citra digital memiliki tampilan visual yang memuaskan mata manusia. Ketidakpuasan itu dapat timbul karena adanya gangguan pada kualitas citra (noise), kualitas pencahayaan pada citra digital yang terlalu gelap atau terlalu terang. Dimana noise ini biasanya didapat dari proses digitalisasi citra. Proses digitalisasi citra ini maksudnya adalah proses meng-capture objek didunia nyata kedalam citra digital. Untuk menghilangkan noise tersebut pada citra digital maka diperlukan sebuah metode yang dapat memperbaiki kualitas citra.

Salah satu metode yang digunakan adalah peregangan kontras (Contrast Stretching). Metode Contrast Stretching ini dapat digunakan untuk memperbaiki kualitas citra digital yang berhubungan dengan pencahayaan yaitu dengan mengatur tingkat kecerahan (brightness) maupun kekontrasan dari sebuah citra digital. Misalnya gambar mobil yang diambil dari sebuah kamera handphone menghasilkan kualitas citra yang kurang baik yaitu pencahayaan yang dihasilkan dari 
sebuah kamera digital tersebut terlalu gelap. Dengan menggunakan metode peregangan kontras ini kita dapat memperbaiki kualitas citra tersebut sehingga menghasilkan citra yang kurang baik menjadi citra yang lebih baik.

Sekarang ini banyak aplikasi yang dapat digunakan untuk mengubah atau mengatur tingkat kecerahan (brightness) maupun kekontrasan dari sebuah gambar (image) pada citra digital. Namun pada penelitian kali ini penulis akan membuat program berbasis Borland Delphi 2010 Embarcadero yang dapat mengubah sskekontrasan dari sebuah citra digital.

Untuk merancang aplikasi tersebut peneliti menggunakan metode Contrast Stretching dengan menggunakan bahasa pemrograman Borland Delphi 2010 Embarcadero. Diharapkan dengan adanya aplikasi tersebut dapat meningkatkan kualitas citra yang kurang baik menjadi kualitas citra yang lebih baik.

Berdasarkan latar belakang masalah diatas, maka peneliti dapat identifikasi masalah sebagai berikut:

1. Terdapat citra digital yang memiliki banyak noise.

2. Kualitas pencahayaan citra masih samar atau kurang jelas.

Batasan masalah dari penelitian ini adalah sebagai berikut:

1. Penggunaan metode Contrast Stretching hanya untuk penajaman citra digital.

2. Perancangan dan pembuatan perangkat lunak ini menggunakan bahasa pemrograman Borland Delphi 2010 Embarcadero.

3. File citra yang digunakan berformat $b m p$ dan jpg.

4. Citra yang digunakan adalah jenis Citra Warna.

5. Perbandingan nilai penyebaran Citra awal dan hasil dapat dilihat melalui Histogram.

6. Aplikasi ini menggunakan Metode Contrast Stretching yaitu dengan cara menentukan nilai-nilai $\mathrm{c} 1, \mathrm{~d} 1, \mathrm{c} 2$, dan $\mathrm{d} 2$ untuk mendapatkan kontras yang baru.

Adapun tujuan penelitian yang ingin dicapai adalah sebagai berikut:

1. Mengimplementasikan Metode Contrast Stretching untuk penajaman citra digital menggunakan bahasa pemrograman Borland Delphi 2010 Embarcadero.
2. Sistem dapat memperbaiki kontras dari sebuah image agar bagian yang terlalu gelap menjadi terang dengan menggunakan Metode Contrast Stretching.

3. Untuk membuat aplikasi penajaman citra digital dengan metode Contrast Stretching agar menarik dan mudah digunakan oleh user.

Manfaat dari penelitian ini dapat dibagi ke dalam 2 kategori, yaitu:

1. Bagi Umun

a. Mengatasi kekontrasan citra yang kurang baik menjadi citra yang lebih baik.

2. Bagi Penulis

a. Menambah pegetahuan dan memperluas wawasan.

b. Dengan penelitian, mahasiswa diharapkan bisa menerapkan keilmuan yang diperoleh dibangku kuliah.

c. Untuk menambah wawasan mengenai implementasi Metode Contrast Stretching serta sebagai penerapan dari ilmu yang diperoleh dibangku perkuliahan pada keadaan yang sebenarnya.

\section{METODE PENELITIAN}

Kontras suatu citra adalah distribusi piksel terang dan gelap. Citra grayscale dengan kontras rendah maka akan terlihat terlalu gelap, terlalu terang, atau terlalu abu-abu. Histogram citra dengan kontras rendah, semua piksel akan terkonsentrasi pada sisi kiri, sisi kanan, atau tengah. Semua piksel akan terkelompok secara rapat pada suatu sisi tertentu dan menggunakan sebagian kecil dari semua kemungkinan nilai piksel.

Citra dengan kontras tinggi memiliki daerah gelap dan terang yang luas. Histogram citra dengan kontras tinggi memiliki dua puncak besar. Satu puncak terkonsentrasi pada sisi kanan histogram.

Citra dengan kontras yang bagus menampilkan rentangan nilai piksel yang lebar. Histogramnya relatif menunjukkan distibusi nilai piksel yang seragam, tidak memiliki puncak utama, atau tidak memiliki lembah.

Perenggangan kontras adalah teknik yang sangat berguna untuk memperbaiki kontras citra terutama citra yang memiliki kontras rendah. Teknik ini bekerja dengan baik pada citra yang memiliki distribusi Gaussian atau mendekati distribusi Gaussian. 
Pada perenggangan kontras, setiap piksel pada citra $U$ ditransformasi dengan menggunakan fungsi berikut :

$$
o(i, j)=\frac{u(i, j)-c}{d-c}(L-1)
$$

Dengan o(i, j) dan $u(i, j)$ berturut-turut piksel sesudah dan sebelum ditransformasi pada koordinat (i, j), c dan $\mathrm{d}$ berturut-turut menyatakan nilai maksimum dan minimum dari piksel citra input, dan L menyatakan nilai grayscale maksimum. Bila nilai piksel lebih lebih kecil dari 0 maka akan dijadikan 0 dan bila lebih lebar dari $(\mathrm{L}-1)$ maka akan dijadikan ( $\mathrm{L}-1)$.

Contrast stretching ini adalah teknik yang digunakan untuk mendapatkan citra baru dengan kontras yang lebih baik daripada kontras dari citra asalnya. Citra yang memiliki kontras rendah dapat terjadi karena kurangnya pencahayaan, kurangnya bidang dinamika dari sensor citra, atau kesalahan setting pembuka lensa pada saat pengambilan citra. Ide dari proses Contrast stretching adalah untuk meningkatkan bidang dinamika dari gray level di dalam citra yang akan diproses.

Proses Contrast Stretching termasuk proses perbaikan citra yang bersifat point processing, yang artinya proses ini hanya tergantung dari nilai intensitas (gray level) satu pixel, tidak tergantung dari pixel lain yang ada di sekitarnya. Gambar menunjukkan transformasi tipikal yang digunakan untuk Contrast Stretching.

Disini diasumsikan bahwa citra memiliki range gray level dari 0 sampai 255 . Pada gambar 1 , c adalah gray level dari citra sebelum diproses dan $\mathrm{d}$ adalah gray level dari citra setelah diproses. Titik $(\mathrm{c} 1, \mathrm{~d} 1)$ dan titik $(\mathrm{c} 2, \mathrm{~d} 2)$ akan menentukan bentuk dari fungsi transformasi, dan dapat diatur untuk menentukan tingkat penyebaran gray level dari citra yang dihasilkan.

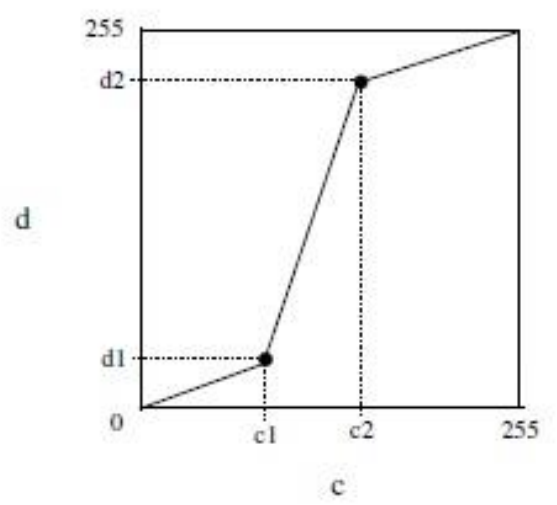

Gambar 1. Fungsi Contrast Stretching

Jika $\mathrm{c} 1=\mathrm{c} 2$ dan $\mathrm{d} 1=\mathrm{d} 2$ maka transformasi akan berbentuk garis lurus yang berarti tidak ada perubahan gray level pada citra yang dihasilkan. Secara umum diasumsikan $\mathrm{c} 1<=\mathrm{c} 2$ dan $\mathrm{d} 1<=\mathrm{d} 2$ sehingga fungsi akan menghasilkan nilai tunggal dan nilainya akan selalu naik. Untuk menghitung nilai hasil transformasi tersebut, kita dapat membuat tiga fungsi sebagai berikut:

Untuk $0<\mathrm{c}<\mathrm{c} 1$, maka d = c . (d1 / c1)

Untuk $\mathrm{c} 1<\mathrm{c}<\mathrm{c} 2$, maka $\mathrm{d}=\mathrm{d} 1+((\mathrm{c}-\mathrm{c} 1)$. $((\mathrm{d} 2-\mathrm{d} 1) /(\mathrm{c} 2-\mathrm{c} 1)))$

Untuk c2 $<\mathrm{c}<255$, maka $\mathrm{d}=\mathrm{d} 2+($ (c-c2) . $(255-\mathrm{d} 2) /(255-\mathrm{c} 2))$

Keterangan :

$\mathrm{c}=$ nilai pixel awal

$\mathrm{d}=$ nilai pixel hasil

$\mathrm{c} 1=$ nilai batas bawah $\mathrm{x}$

$\mathrm{c} 2=$ nilai batas atas $\mathrm{x}$

$\mathrm{d} 1=$ nilai batas bawah $\mathrm{y}$

$\mathrm{d} 2=$ nilai batas atas $\mathrm{y}$

Contoh citra yang akan di proses :

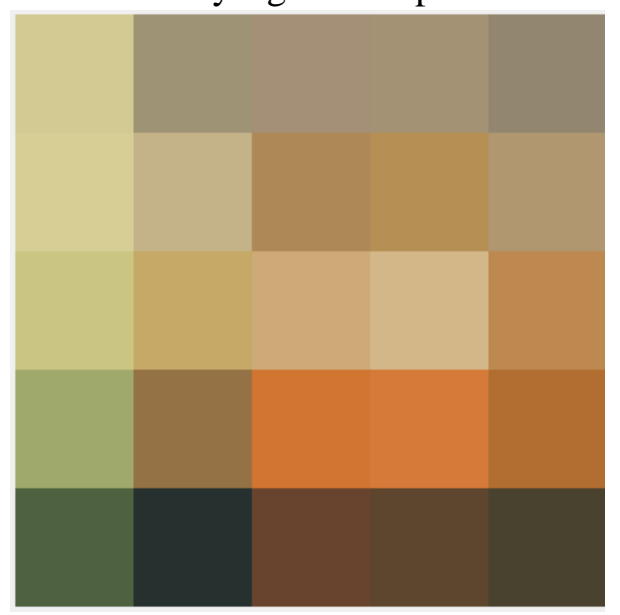

Gambar 2. Citra berukuran 5x5 pixel

Keterangan :

Gambar 2 adalah gambar yang akan di proses.

Diketahui: $\mathrm{c} 1=70$

$$
\begin{aligned}
& \text { d } 1=35 \\
& \mathrm{c} 2=185 \\
& \mathrm{~d} 2=220
\end{aligned}
$$




\section{Nilai Pixel RGB Awal}

Tabel 1 Nilai pixel RGB awal

\begin{tabular}{|l|l|l|l|l|}
$\mathrm{R}=211$ & $\mathrm{R}=159$ & $\mathrm{R}=163$ & $\mathrm{R}=163$ & $\mathrm{R}=147$ \\
$\mathrm{G}=202$ & $\mathrm{G}=147$ & $\mathrm{G}=144$ & $\mathrm{G}=146$ & $\mathrm{G}=134$ \\
$\mathrm{~B}=147$ & $\mathrm{~B}=118$ & $\mathrm{~B}=119$ & $\mathrm{~B}=115$ & $\mathrm{~B}=112$ \\
$\mathrm{R}=215$ & $\mathrm{R}=196$ & $\mathrm{R}=175$ & $\mathrm{R}=181$ & $\mathrm{R}=177$ \\
$\mathrm{G}=206$ & $\mathrm{G}=178$ & $\mathrm{G}=136$ & $\mathrm{G}=143$ & $\mathrm{G}=151$ \\
$\mathrm{~B}=150$ & $\mathrm{~B}=136$ & $\mathrm{~B}=88$ & $\mathrm{~B}=84$ & $\mathrm{~B}=111$ \\
$\mathrm{R}=202$ & $\mathrm{R}=198$ & $\mathrm{R}=205$ & $\mathrm{R}=212$ & $\mathrm{R}=190$ \\
$\mathrm{G}=197$ & $\mathrm{G}=169$ & $\mathrm{G}=170$ & $\mathrm{G}=183$ & $\mathrm{G}=137$ \\
$\mathrm{~B}=131$ & $\mathrm{~B}=103$ & $\mathrm{~B}=118$ & $\mathrm{~B}=136$ & $8=80$ \\
$\mathrm{R}=160$ & $\mathrm{R}=148$ & $\mathrm{R}=209$ & $\mathrm{R}=214$ & $\mathrm{R}=178$ \\
$\mathrm{G}=169$ & $\mathrm{G}=114$ & $\mathrm{G}=117$ & $\mathrm{G}=122$ & $\mathrm{G}=110$ \\
$\mathrm{~B}=108$ & $\mathrm{~B}=69$ & $\mathrm{~B}=49$ & $\mathrm{~B}=57$ & $\mathrm{~B}=49$ \\
$\mathrm{R}=78$ & $\mathrm{R}=37$ & $\mathrm{R}=104$ & $\mathrm{R}=94$ & $\mathrm{R}=73$ \\
$\mathrm{G}=98$ & $\mathrm{G}=48$ & $\mathrm{G}=67$ & $\mathrm{G}=69$ & $\mathrm{G}=66$ \\
$\mathrm{~B}=64$ & $\mathrm{~B}=47$ & $\mathrm{~B}=45$ & $\mathrm{~B}=45$ & $\mathrm{~B}=47$ \\
\hline
\end{tabular}

Keterangan :

Tabel 1 adalah tabel nilai pixel $R G B$ yang di ambil dari gambar citra berukuran $5 \times 5$ pixel

$$
\begin{aligned}
& \mathrm{c} 2<\mathrm{c}<255=185<211<255 \\
& \mathrm{~d}=\mathrm{d} 2+((\mathrm{c}-\mathrm{c} 2) .((255-\mathrm{d} 2) /(255-\mathrm{c} 2))) \\
& =220+((211-185) .(((255-220) /(255-
\end{aligned}
$$

185)) )

$$
\begin{aligned}
& =220+((26) \cdot((35 / 70))) \\
& =220+((26) \cdot(0,5)) \\
& =220+13 \\
\mathrm{~d} & =233
\end{aligned}
$$

$c 2<\mathrm{c}<255=185<202<255$

$$
\mathrm{d}=\mathrm{d} 2+((\mathrm{c}-\mathrm{c} 2) .((255-\mathrm{d} 2) /(255-\mathrm{c} 2)))
$$$$
=220+((202-185) \cdot(((255-220) /(255-
$$

185)) )

$$
\begin{aligned}
&=220+((17) \cdot((35 / 70))) \\
&=220+((17) \cdot(0,5)) \\
&=220+8,5 \\
& \mathrm{~d}=228 \\
& \mathrm{c} 1<\mathrm{c}<\mathrm{c} 2=70<147<185 \\
& \mathrm{~d}=\mathrm{d} 1+((\mathrm{c}-\mathrm{c} 1) .((\mathrm{d} 2-\mathrm{d} 1) /(\mathrm{c} 2-\mathrm{c} 1))) \\
&=35+((147-70) .((220-35) /(185-
\end{aligned}
$$

70)) )

$$
\begin{aligned}
& =35+((77) \cdot((185) /(115))) \\
& =35+((77) \cdot(1,6)) \\
& =35+123,2 \\
\mathrm{~d} & =158,2(158)
\end{aligned}
$$

Nilai Pixel RGB Hasil Contrast Stretching

Tabel 2. Nilai pixel $R G B$ hasil

\begin{tabular}{|l|l|l|l|l}
$\mathrm{R}=233$ & $\mathrm{R}=177$ & $\mathrm{R}=184$ & $\mathrm{R}=184$ & $\mathrm{R}=158$ \\
$\mathrm{G}=228$ & $\mathrm{G}=158$ & $\mathrm{G}=153$ & $\mathrm{G}=157$ & $\mathrm{G}=137$ \\
$\mathrm{~B}=158$ & $\mathrm{~B}=112$ & $\mathrm{~B}=113$ & $\mathrm{~B}=107$ & $\mathrm{~B} 102$ \\
$\mathrm{R}=235$ & $\mathrm{R}=225$ & $\mathrm{R}=203$ & $\mathrm{R}=213$ & $\mathrm{R}=206$ \\
$\mathrm{G}=230$ & $\mathrm{G}=208$ & $\mathrm{G}=141$ & $\mathrm{G}=152$ & $\mathrm{G}=165$ \\
$\mathrm{~B}=163$ & $\mathrm{~B}=141$ & $\mathrm{~B}=64$ & $\mathrm{~B}=57$ & $\mathrm{~B}=101$ \\
$\mathrm{R}=228$ & $\mathrm{R}=226$ & $\mathrm{R}=230$ & $\mathrm{R}=233$ & $\mathrm{R}=224$ \\
$\mathrm{G}=226$ & $\mathrm{G}=193$ & $\mathrm{G}=195$ & $\mathrm{G}=216$ & $\mathrm{G}=142$ \\
$\mathrm{~B}=133$ & $\mathrm{~B}=88$ & $\mathrm{~B}=112$ & $\mathrm{~B}=141$ & $\mathrm{~B}=51$ \\
$\mathrm{R}=179$ & $\mathrm{R}=160$ & $\mathrm{R}=323$ & $\mathrm{R}=234$ & $\mathrm{R}=208$ \\
$\mathrm{G}=193$ & $\mathrm{G}=105$ & $\mathrm{G}=110$ & $\mathrm{G}=118$ & $\mathrm{G}=99$ \\
$\mathrm{~B}=96$ & $\mathrm{~B}=34$ & $\mathrm{~B}=24$ & $\mathrm{~B}=28$ & $\mathrm{~B}=24$ \\
$\mathrm{R}=49$ & $\mathrm{R}=18$ & $\mathrm{R}=94$ & $\mathrm{R}=73$ & $\mathrm{R}=40$ \\
$\mathrm{G}=80$ & $\mathrm{G}=24$ & $\mathrm{G}=33$ & $\mathrm{G}=34$ & $\mathrm{G}=33$ \\
$\mathrm{~B}=32$ & $\mathrm{~B}=23$ & $\mathrm{~B}=22$ & $\mathrm{~B}=22$ & $\mathrm{~B} 23$ \\
& & &
\end{tabular}

Keterangan :

Tabel 2 diatas adalah tabel nilai pixel baru $R G B$ setelah dilakukannya proses Contrast Stretching. 


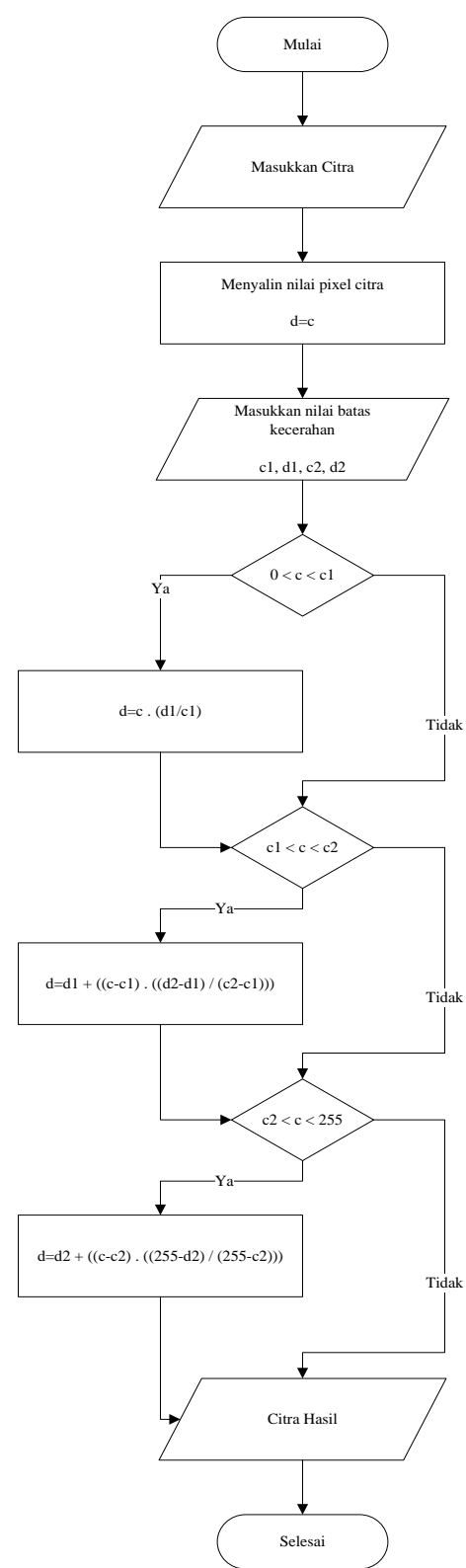

Gambar 3. Flowchart Algoritma Contrast Stretching

Pada gambar 3 merupakan gambaran dari alur flowchart algoritma Contract Stretching. Pada gambar 4 menggambarkan tentang Use Case Diagram aplikasi.

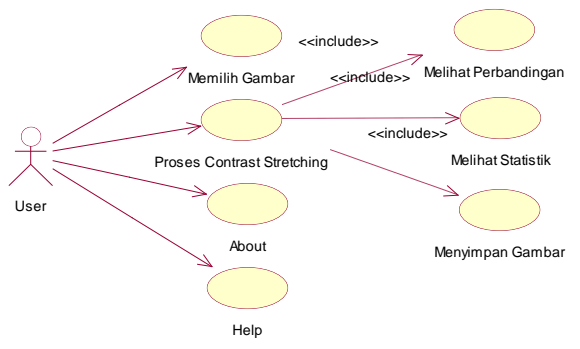

Gambar 4. Use Case Diagram

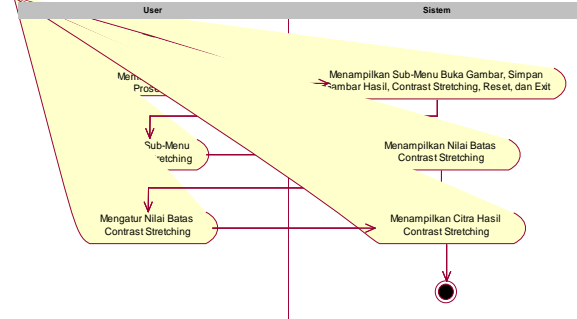

Gambar 5. Activity Diagram

Pada gambar 5 merupakan gambaran dari activity diagram aplikasi yang dibangun untuk penajaman kualitas citra.

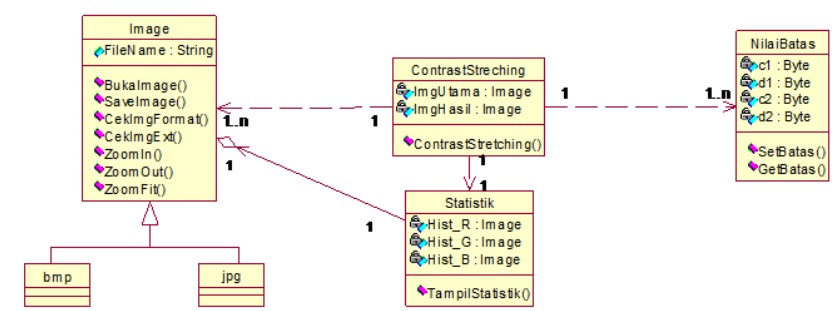

Gambar 6. Class Diagram

Pada gambar 6 merupakan gambaran dari class diagram aplikasi yang dibangun untuk penajaman kualitas citra.

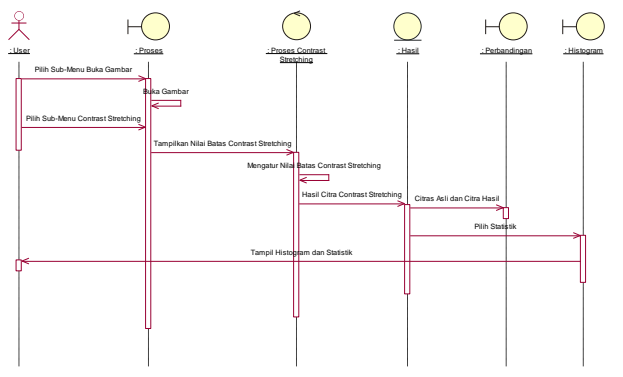

Gambar 7. Sequence Diagram

Pada gambar 7 merupakan gambaran dari sequence diagram aplikasi yang dibangun untuk penajaman kualitas citra.

\section{HASIL DAN PEMB AHASAN}

Setelah mengalami sederetan proses iterasi, pada tahapan Construction ini sudah dapat menghasilkan suatu aplikasi. Gambar 8 merupakan gambar dari proses Contrast Streatching yang sedang berjalan. 


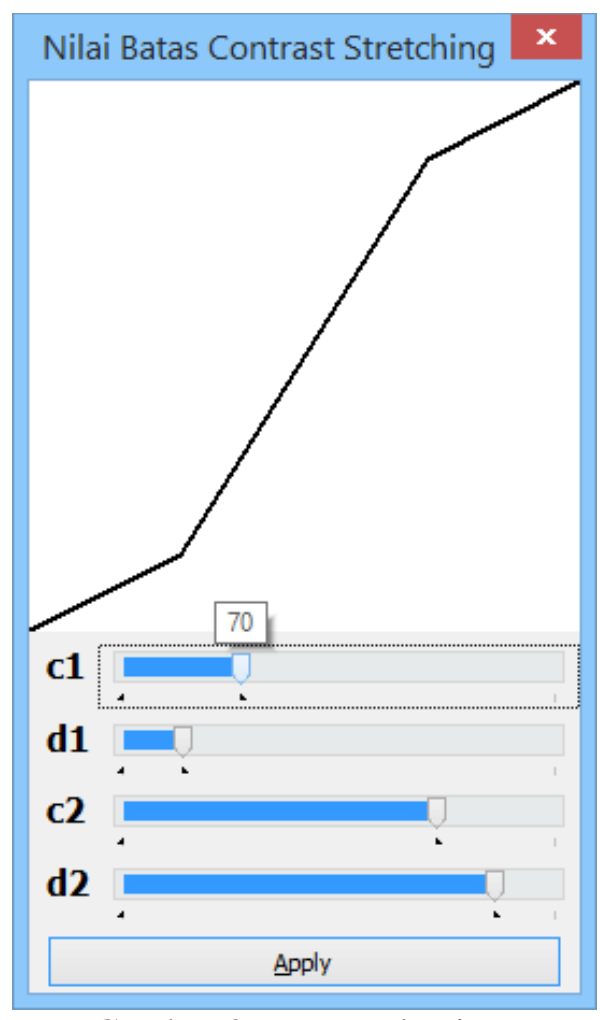

Gambar 8. Proses algoritma

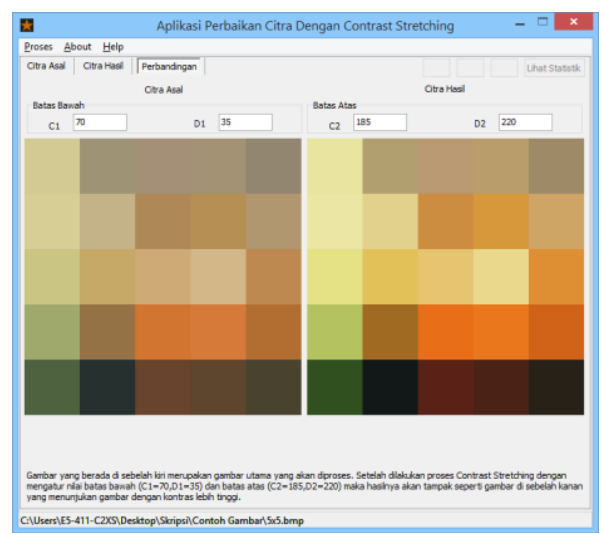

Gambar 9. Hasil perbandingan

Pada gambar 9 merupakan hasil perbandingan gambar setelah menggunakan algoritma contrast streatching.

\section{KESIMPULAN}

Kesimpulan yang diambil penulis setelah mengimplementasikan metode Contrast Stretching ini adalah sebagai berikut :

1. Contrast Stretching digunakan untuk melakukan perbaikan citra digital menjadi citra yang memiliki kualitas bagus.

2. Sistem dapat memperbaiki kontras sebuah citra dengan menentukan nilai $\mathrm{c} 1, \mathrm{~d} 1, \mathrm{c} 2$, dan $\mathrm{d} 2$.
3. Jika citra memiliki kontras rendah histogram citranya memiliki bentuk yang sempit yang menunjukkan bahwa citra memiliki dynamic

\section{SARAN}

Setelah mengimplementasikan metode Contrast Stretching pada skripsi ini penulis dapat memberikan beberapa saran antara lain :

1. Pada sistem yang telah dibuat format file citra yang bisa digunakan adalah citra yang berformat .bmp dan .jpg. Untuk pengembangan selanjutnya dapat menggunakan format citra yang lain.

2. Di dalam perancangan dan pembuatan metode Contrast Stretching ini sebaiknya disempurnakan dalam segi tampilan sehingga tampilan ini tampak lebih menarik (user friendly).

\section{DAFTAR PUSTAKA}

Al Fatta, H. (2007). Analisis dan Perancangan Sistem Informasi untuk Keunggulan Bersaing Perusahaan dan Organisasi Modern. Yogyakarta : CV. Andi Offset.

Darmawan Erico, H. (2006). "Perancangan Mini Image Editor Versi 1.0 sebagai aplikasi Penunjang Mata Kuliah Digital Image Processing",, Volume 2(2), 10 Halaman.

Gonzalez,Rafael C, Woods, Richard E. (1993). Digital Image Processing. AddisonWesley Publishing Company Inc., USA.

Munir, R. (2004). Pengolahan Citra Digital Dengan Pendekatan Algoritmik. Bandung : Informatika.

Nugroho, Adi. 2005. "Analisis dan Perancangan Sistem Informasi dengan Metodologi Berorientasi Objek". Bandung: Informatika.

Putra, D. (2009). Pengoahan Citra Digital, Yogyakarta : C.V ANDI OFFSET.

Rosa-Shalahuddin, A. S. M. 2013. Rekayasa Perangkat Lunak Terstruktur dan 
Berorientasi Objek. Bandung : Informatika.

Ruslan, R. (2003). Metode Penelitian PR dan Komunikasi. Jakarta : PT Raja Grafindo Persada.

Septian, D. (2010). Implementasi Kebijakan Peraturan Pemerintah Nomor 98 Tahun 2000 Tentang Pengadaan Pegawai Negeri Sipil Di Badan Cianjur. Bandung. Universitas Komputer Indonesia.

Setyo, N. (2005). "Implementasi Metode Contrast Stretching Untuk Memperbaiki Kontras Citra". Laporan Penelitian Jurusan Teknik Informatika STIKOM, Balikpapan.

Siahaan, D. (2012). Analisis Kebutuhan Dalam Rekayasa Perangkat Lunak (edisi pertama). Yogyakarta : ANDI.

Supardi, Y. (2013). Koleksi Program Tugas Akhir dan Skripsi dengan FoxPro 9. Jakarta : PT Elex Media Komputindo.

Sutoyo, T,. Et. Al. (2009). Teori Pengolahan Citra Digital. Semarang : ANDI Yogyakarta dengan UDINUS Semarang. 